DOI 10.37882/2223-2982.2021.01.40

\title{
СРЕДСТВО ОБОЗНАЧЕНИЯ ВОЗРАСТА В РУССКОМ И КИТАЙСКОМ ЯЗЫКЕ
}

\section{MEANS OF INDICATING AGE IN RUSSIAN AND CHINESE}

Yan Zhuo

Summary: It is known that at the beginning of the XX century, there was an increased interest in gender aspects. Many linguists noted the need to study the speech of people of different ages and social strata. $G$. Paul noted that «there are as many separate languages as there are individuals». On the basis of the so-called "primitive languages» began to accumulate experience in studying the differences between male and female versions of the language, later it began to move to the «civilized» European languages: English, French, German. And already at the end of the XX century, a separate direction of sociolinguistic research was finally formed - gender linguistics, which considers all types of language and speech variation that are due to the gender of native speakers. Currently, the term «gender» is widely used in linguistics. This article examines the gender specificity of the concept of age on the example of the Russian and Chinese languages.

Keywords: gender linguistics, language picture of the world, concept, Chinese, Russian, gender, age.
И зучение понятийных категорий и их вербализации в языке осуществляются в рамках новейших направлений современной лингвистики - лингвокультурологического и когнитивного подходов к языку, в Связи с чем одной из актуальных проблем этого направления становится задача выявления национально-культурных и социально-групповых картин мира (см., например: Н.Ф. Алефиренко, Ю.Д. Апресян, Н.Д. Арутюнова, Т.А. Булыгина, А.Д. Шмелев, А. Вежбицкая, А.А. Залевская, Ю.Н. Караулов, В.И. Карасик, В.Т. Клоков, В.В. Колесов, Е.С. Кубрякова, Д.С. Лихачев, З.Д. Попова, И.А. Стернин, Г.Г. Слышкин, Н.В. Уфимцева, Г.И. Берестнев и др.).

Терминология понятия «возраст», играет важную роль в концептуализации мира, поскольку на основе представлений, знаний, оценок, связанных с возрастными периодами жизни человека, происходит осмысление различных явлений действительности. В связи с этим безусловную актуальность приобретают исследования различных аспектов указанного понятия. Однако в большинстве работ данного направления выявляется национальная специфика возрастных концептов посредством сравнения их вербализаций в разных языках (Н.В. Крючкова, Е.И. Бондаренко, Д. Кацкова, Ю.В. Матвеев, Н.А. Серебрякова), анализируется разница в объеме и границах

\author{
Янь Чжо \\ Аспирант, Московский государственный университет \\ имени М.В. Ломоносова \\ yanzhuo524@mail.ru
}

Аннотация: Известно, что в начале XX века возрос интерес к гендерным аспектам. Многие учёные-лингвисты отмечали необходимость изучать речь людей разных возрастов и слоёв общества. Г. Пауль отмечал, что «на свете столько же отдельных языков, сколько и индивидов». На базе так называемых «примитивных языков» стал накапливаться опыт изучения расхождений между мужскими и женскими вариантами языка, позже он стал перемещаться на «цивилизованные» европейские языки: английский, французский, немецкий. И уже в конце XX века окончательно сформировалось отдельное направление социолингвистических исследований - гендерная лингвистика, рассматривающая все виды языкового и речевого варьирования, которые обусловлены полом носителей языка. В настоящее время термин «гендерный» достаточно широко используется в лингвистике. В данной статье исследуется гендерная специфика концепта возраст на примере русского и китайского языков.

Ключевые слова: гендерная лингвистика, языковая картина мира, концепт, китайский язык, русский язык, пол, возраст.

обозначаемых понятий в разных языковых сообществах (В.Г. Гак), исследуются преимущественно частные возрастные концепты на разножанровом языковом материале (А.Т. Ашхарова) либо разные концепты в рамках одного жанра (Н.Н. Кузнецова), проводятся диахронические и региональные исследования по данной проблематике (Е.И. Зиновьева, Г.И. Любимова).

Изучение возраста во многом связано с гендерной лингвистикой (лингвистическая гендерология). Она является научной областью в рамках междисциплинарных гендерных исследований, которые используют языковые концептуальные устройства для изучения гендера (социокультурного гендера, понимаемого как традиционная структура, относительно независимая от биологического пола).

О.В Эперсон в 1922 году в своей фундаментальной работе о происхождении и развитии языка Эсперсен посвятил целую главу изучению особенностей языковой компетентности женщин. Он обратил внимание на то, что женщины используют разные слова, чем мужчины, более тактичны и менее ругаются. По словам Эсперсена, женщины консервативны в использовании языка, о чем свидетельствуют примеры общин иммигрантов и других 
изолированных групп, которые сохранили свой родной язык, изучая новый язык. В то же время женщины с большей вероятностью останутся одноязычными, а мужчины быстрее осваивают новый язык. Однако не учитывается тот факт, что мужчины, изучающие иностранный язык, диктуют необходимость работать и интерпретировать себя на новом языке. Женщины, живущие в более частной домашней обстановке, не должны этого делать.

Хотя Эсперсон наиболее полно объяснил гендерные последствия, его взгляды подверглись критике в последующие периоды, поскольку он делал выводы только на основе личных наблюдений, многие из которых не были полностью подтверждены.

В целом, первый этап изучения гендерных факторов в языке имеет две особенности:

а) изучение нерегулярности, находящейся на грани лингвистики;

б) формирование понятия «дефицит» в «женском» языке по отношению к «мужскому» в процессе описания особенностей языковой компетентности у мужчин и женщин. Норма считается «мужским» языком, а отклонение от нормы - «женским».

Более интенсивные и систематические гендерные исследования начались в 1960-х годах. Их стимулировало развитие социолингвистики, которая предоставила ученым обширные статистические данные о функциях языка в группах населения, объединенных по профессии, полу, возрасту, городскому или сельскому образу жизни. Таким образом, количественные исследования показали, что пол носителей языка оказывает определенное влияние на языковую компетентность. В частности, было обнаружено, что женщины склонны использовать более престижные варианты произношения концепта «возраст».

В конце 60-х и начале 70-х годов гендерные исследования в лингвистике получили мощный импульс из-за так называемого «Движения новых женщин» в США и Германии, что привело к особому направлению в лингвистике, известному как феминистская Лингвистика (FL) или феминистский язык критики. Фундаментальная работа Лакоффа доказывает мужскую концентрацию языка и ошибочный образ женщины в языковом реплицированном образе мира. К особенностям феминистской критики языка можно отнести его ярко выраженный полемический характер, лингвистическое описание всего спектра результатов участия в гуманитарных науках (психология, социология, этнография, антропология, история), а также ряд успешных попыток влиять на языковую политику.

Во Флориде можно увидеть две области: первая касается лингвистических исследований для определения «асимметрии в языковой системе, ориентированной на женщин». Эта асимметрия называется сексистским языком (sprachlicher Sexismus). Речь идет о патриархальных стереотипах, закрепленных в языке и навязывающих говорящим определенную картину мира, в которой женщинам отводятся второстепенные роли, прежде всего, приписываемые негативным качествам.

С конца 1960-х годов в лингвистике (в основном в США и Германии) наблюдается тенденция к феминистской критике, называемой языком, или феминистской лингвистикой.

Феминистская Лингвистика критикует возраст за его андроцентричность, то есть его ориентацию не на человека в целом, а на человека. Язык обвиняется в сексизме в отношении женщин. Дискриминация проявляется в преобладании мужских форм в языке, вторичности и противопоставлении женщин, совпадении понятий»человек»и»человек» во многих языках, преобладании негативных рейтингов в женских именах. Рассуждение основано на гипотезе Сепира-Уорфа о релятивизме языка: языковая структура и направленное мышление, поэтому человеческое сознание во многом зависит от особенностей языка. Феминистская Лингвистика сделала много предложений для языковой реформы.

Сегодня можно говорить о существовании адекватных гендерных исследований, изучающих гендерные, а точнее гендерные различия между процессами социального строительства. Гендер рассматривается как институционализированная и ритуализованная социокультурная структура - один из параметров социальной идентичности личности. Социальные институты (армии, школы) поддерживают различия, наделяют их нормативным статусом и интерпретируют их как естественно определенные. Социальные ритуалы также создают гендерную асимметрию в одежде, повседневном использовании и символике. Гендер как продукт культуры отражает представления людей о женственности и мужественности, записанные в фольклоре, сказках, традициях и языках. В коллективном сознании возникают гендерные стереотипы - упрощение и обострение представлений о природе и качествах людей другого пола.

В общем, гендерные исследования в лингвистике связаны с двумя проблемами.

1. Возраст и гендерная рефлексия. Целью данного подхода является описание и объяснение того, как люди, проявляющие равный пол в языке (в основном изучающие номинативную систему, лексику, грамматику, гендерные категории), приписывают эти оценки мужчинам и женщинам и в каких семантических областях они наиболее четко выражены.

2. Различаются речевое и общечеловеческое пове- 
дение мужчин и женщин, типичные стратегии и тактики, выбор лексических единиц по полу, способы достижения успеха в общении, выбор лексических предпочтений, синтаксических структур-специфики мужской и женской речи.

При изучении речевого и коммуникативного поведения в целом пол рассматривается как один из параметров построения социальной идентичности говорящего в общении. Он обычно взаимодействует с другими параметрами: статусом, возрастом и социальной группой. Одна из самых известных работ в этой области - Дебора Таннен «ты меня не понимаешь». Женщины и мужчины ведут диалог». Анализируются коммуникативные неудачи людей разного пола, объясняются различные требования общества к мужчинам и женщинам, а также особенности социализации детей и подростков, когда общение происходит преимущественно в однополых группах. Под влиянием этих факторов у мужчин и женщин развиваются разные поведенческие мотивы, разные стратегии и коммуникативные стратегии. Речевое поведение мужчины, как правило, направлено на достижение и поддержание независимости и высокого положения. Общество ожидает, что женщины будут неконфронтационными, послушными и эмоциональными.

Большой интерес вызывает исследование гендерных проблем в профессиональной коммуникации. Таким образом, в результате многолетней работы немецких лингвистов по изучению гендерной специфики профессиональной коммуникации было установлено, что мужчины и женщины проявляют склонность к различным стилям дебатов. Мужчины с меньшей вероятностью соглашаются на критику, чаще прибегают к сатире, цитируют авторитеты, используют меньше речевых инструментов, выражают неуверенность и тем самым создают впечатление более компетентного и уверенного в себе специалиста.

Возникновение гендерных исследований в русской лингвистике, как правило, относится к середине 1990-х годов. В этот период в российской научной литературе появился термин «пол», а отечественные читатели могли ознакомиться с зарубежными теоретическими трудами по гендерным вопросам. Русская Лингвистика не игнорировала гендерную проблему, а рассматривала ее в рамках других языковых дисциплин (еще до появления гендерной терминологии). Эти исследования не были систематическими, не претендовали на статус научного направления и не ассоциировались с теорией социального конструктивизма, но отечественные ученые внесли свой вклад в развитие проблем, которые впоследствии были приняты институтом гендера.

В определенной степени исследования возраста можно разделить на следующие области.
1. Психолингвистическое и социолингвистическое исследование, изучающее особенности письменных и устных текстов мужского и женского пола, влияние половых и возрастных особенностей говорящего на процессы речевого общения, гендерную специфику речевого восприятия, влияние гендерных факторов на поведение. Изучено семейное общение интеллигенции в Москве.

1) характерная черта текстообразования, свойственная женщине - в том числе и в процессе разговорного субъекта, вызывающего ситуации, порождающие речевые движения речи.

2) человеку труднее переключаться, увлекаться обсуждаемой темой, не отвечать на несвязанные замечания.

3) женщины с большей вероятностью ссылаются на личный опыт и приводят конкретные случаи из опыта их непосредственной среды.

4) для мужской речи характерны также терминология, стремление к точности номинации, более сильное влияние фактора «карьера»(считается, что мужчины больше говорят о работе), более склонность к использованию выразительности, особенно стилистически уменьшенной выразительности.

5) типичные черты женской речи включают в себя преувеличенную выразительность (страшное наступление) и более частое употребление междометий типа О-о!

6) ассоциативное поле мужской и женской речи связано с различными фрагментами картины мира: спортивной, охотничьей, профессиональной, военной (мужской) и природной, животной, повседневной (женской).

7) у женщин есть четкая тенденция к усилению, в основном положительной оценки. Мужчины используют более выраженные, отрицательные отзывы, в том числе стили, которые уменьшают ругательство.

В качестве основного вывода автор отмечает отсутствие резкой «непреодолимой» границы между мужской и женской речью в русском языке. Особенности мужской и женской речи, которые они отмечают, определяются как тенденции использования.

Возраст - это «фундаментальная антропологическая характеристика» [3], при его концептуализации он может рассматриваться как биологический параметр, «общественный фактор» и «культурное явление» [3]. И в китайском, и в русском слова «возраст» употребляются схожим образом. В обоих случаях они обозначают длительность существования человека, животного, растения, неживых объектов [1].

Слово 年龄nián líng 'возраст' состоит из иероглифов 
年nián и 龄líng. Иероглиф 年nián состоит из двух частей: 禾hé 'зерно' и 千qiān (фонетик, не несущий смысловой нагрузки). 年 значит «посевы созрели, время сбора урожая» [9]. (Ср. русский корень -рост-, такие слова, как «зрелость» и «незрелость», «расцвет» и «увядание» и т. п.) Второй иероглиф 龄líng также состоит из двух частей: 齿cȟ̌ 'зубы' и фонетик 令lìng.

В китайском языке есть много слов, которые описывают возраст и связаны с зубами, например: 壮齿 zhuàng chǐ 'крепкие зубы' («взрослый») и 衰齿 shuāi ch ̌ 'слабые зубы' («старый»). Таким образом, круг ассоциаций с самим словом «возраст» в китайском языке шире, чем в русском. Тем не менее, и лексические, и этимологические характеристики вполне сопоставимы. Рассмотрим проблему возрастных номинаций женщин в китайском языке.

Традиционные представления о женском возрасте напрямую связаны с браком. Так, в Древнем Китае девушка считалась совершеннолетней в пятнадцать лет. Ритуал совершеннолетия сопровождался сменой прически. Иероглиф 笄јі ‘шпилька, используемая для традиционной прически' присутствует в группе слов, обозначающих достигшую пятнадцатилетия девушку: 初䈂 chū ji, 始 䈂 shǐ jī, 加䈂 jiā jī, 䈂总 jïzǒng. В китайской фразеологии молодость ассоциируется с красотой, привлекательностью, любовными переживаниями: 黄花少年，豆冦年华 huánghuā shàonián'золотая пора девичьей юности'; 少女 怀春 shàonü huáichūn 'молодая девушка думает о любви'; 窈宛淑女，君子好述 yăotiǎo shūnü, jūnzl hăoqiú 'красивая (очаровательная) и скромная (добродетельная, чистая) девушка, и молодцу-сударю - хорошая пара!' [8].

Замужество считается обязанностью взрослой девушки: 男大当婚，女大当嫁 nán dà dāng hūn, nü dà dāng jià 'когда мужчина вырастает, ему нужно жениться вовремя; когда девушка вырастает, ей нужно выйти замуж вовремя' [4]; 女大不中留 nü dà bù zhōng liú 'выросшую девушку не следует задерживать дома (т. е. нужно выдать замуж)' [8]. Не вступившая в брак девушка традиционно воспринимается как «человек, не достигший к определенному моменту соответствующего социального статуса и не обладающий характерными для данного статуса свойствами» $[5$, с. 50].

Рассмотрим, как это представление отражено в картине мира современных носителей китайского языка. В «Докладе о языковой жизни Китая», опубликованном Министерством образования в 2006 году, в список 171 новых китайских слов попало выражение 大龄剩女 dàlíng shèngnü̆. Его можно перевести как «лишние женщины», или «женщины-остатки». Оно обозначает незамужнюю женщину (около 27 лет), которой по возрасту уже следовало бы состоять в браке, но ее шансы на это ниже, чем у более молодых.
Ранее в китайском языке уже существовало устойчивое выражение 老处女lăo chùnü, аналогичное русскому «старая дева», но гораздо более грубое. Как и в русском языке, это «фразеологическое единство», возникшее «в результате метафоризации и поэтому отмеченное образной мотивацией» [4, с. 51] с «отрицательным значением'женщина, которая не вышла замуж'» [6].

В компонентах фразеологической единицы отрицательные коннотации выражены явно: 老 lăо'старый' в наименованиях человека может иметь грубый, сниженный оттенок (ср. 老家亲 'старый осёл'), 处女 chù nü 'девственница' подчеркивает именно физиологическое состояние женщины. По своей форме 大龄剩女 dàlíng shèngnü воспроизводит типично китайские фразеологизмы.

В отличие от 老处女lăo chùnü, его компоненты сами по себе не относятся к сниженной лексике, оставаясь в рамках норм литературного языка: 大龄 dàlíng 'молодые люди в пределах 30 лет', 剩shèng 'излишек, остаток', 女 nü 'относящийся к женщине'.

Отрицательно-иронический смысл несет употребление слова 剩shèng в качестве характеристики человека. Отметим, что, несмотря на негативный характер номинации, возможны и употребления в позитивном ключе — «женщина, сосредоточенная на карьере». Рассмотрим исторические изменения номинации «женщины».

В китайском языке взрослых женщин называют 妇 女fùnü. Классический словарь «Шовэнь цзецзы» дает следующую интерпретацию древнего начертания иероглифа 妇: женщина подчитняется мужчине, работает по дому, держа веник в левой руке, а совок в правой [9]. (Современное написание 妇 - результат орфографической реформы в КНР). Только женщины, которые могут вступить в брак и рожать, могли называться 妇女fùnü.

Древний иероглиф «женщина» получается, что номинация 妇女fùnü не только обозначает возраст, но и отражает концепцию семейных отношений. В XX веке патриархальные традиции подвергаются критике и постепенно исчезают.

Новый смысл слову 妇女fùnü дала коммунистическая агитация, в частности деятельность революционерки Сян Цзиньюй, основательницы китайского женского движения. Слово обозначает общность представительниц женского пола, употребляется в переводах трудов о «женском вопросе», таких как «Женщина и социализм» А. Бебеля и «Советская власть и положение женщины» В.И. Ленина. Характерны такие употребления, как 妇女运动fùnü yùndòng 'женское движение', 妇女状况 fùnü zhuàngkuàng 'положение женщин', 三八妇女 sānbā yùndòng 'Международный женский день'. 
В конечном счете в партийной риторике 妇女fùnü стали такой же «политической категорией», как, например, «рабочий класс». На сегодняшний день словом 妇 女fùnü в официальных письменных контекстах называют любую женщину старше 14 лет, замужнюю и незамужнюю. Однако для современного носителя языка это слово кажется устаревшим, неактуальным, относящимся одновременно к революционному прошлому и традиционной семье. Назвать женщину 妇女fùnü - значит намекнуть, что она старше и уже не молода.

В повседневной китайской речи можно встретить выражения 家庭妇女jiā tíng fù nü 'семейные женщины', 中年 妇女zhōng nián fù nü 'женщины среднего возраста' и 农 村妇女 nóng cūn fù nü 'деревенские женщины', которые негативно характеризуют женщину по ее возрасту или статусу.

В России допустимо обратиться к незнакомой женщине среднего возраста «девушка». В Китае по отношению к женщинам этого возраста не могут употребляться слова со значением «девушка, девочка», потому что это означает, что говорящий подразумевает, что она может быть «старой девой». Как обращение к незнакомке в разговорном китайском языке используется 美女měinü 'красавица'.

В официальных случаях употребляется 女士'госпожа'. Отметим, что в вышеописанных примерах старший возраст женщины часто выступал негативной характеристикой. В описании мужского возраста ситуация прямо противоположна.

Очень характерен фразеологизм 男子三十杨柳青， 女子三十老婆娘 nánž̌ sānshí yángliǔqīng, nüzǐ sānshí lăo póniáng 'Когда мужчине исполнилось тридцать, он прекрасен, как цветок. Когда женщине тридцать, она уже старуха'.

Такие определения возраста характерны для китайской культуры. Таким образом, можно заметить, что слова и выражения, входящие в поле концепта «Возраст», могут относиться к различным пластам китайской культуры. Анализ возрастных номинаций женщин позволяет заметить гендерную специфику концепта «Возраст»: он включает в себя разницу в восприятии возраста мужчин и женщин, эмоционально-оценочную характеристику возраста.

\section{ЛИТЕРАТУРА}

1. Возраст // Толковый словарь русского языка Дмитриева. URL: https://dic.academic.ru/dic.nsf/dmitriev/493 (дата обращения: 20.05.2018).

2. Гайфуллина А.Н. Концепт «Женщина» в языке женских форумов Рунета // Вестник факультета языка и литературы Университета китайской культуры. 2007. Вып. 10.

3. Диалог культур. Концепции развития лингвистики и лингводидактики / И.К. Кириллова и др. М.: НИУ МГСУ, 2015.

4. Марзук Ф.А. Вербализация понятия «возраст» в паремиях / Ф.А. Марзук // Мир русского слова. 2007. № 1 - 2 .

5. Марзук Ф.А. Особенности употребления слов-названий возрастных периодов в романе Л.Н. Толстого «Война и мир» / Ф.А. Марзук // Русский язык за рубежом. 2007. № 2.

6. Муратова М. Старая дева и стародевичество как культурный концепт // Язык Гендер Традиция: материалы международной научной конференции 25-27 апреля 2002 года. URL: http://www.folk.ru/Research/Conf_2002/muratova.php?rubr=Research-conf (дата обращения: 21.05.2018).

7. Сафонова С., Чупрякова 0., Замалютдинова Э. Наименования женщины в русской фразеосистеме // Филология и культура. 2017. № 4 (50).

8. 大БКPC: Сайт для профессионалов и любителей китайского языка. URL: https://bkrs.info/ (дата обращения: 20.05.2018)

9. 说文解字. URL: http://www.cidianwang.com/shuowenjiezi/ (дата обращения: 20.05.2018).

(с) Янь Чжо (yanzhuo524@mail.ru).

Журнал «Современная наука: актуальные проблемы теории и практики» 